\title{
Tag-Mass: Specific Molecular Imaging of Transcriptome and Proteome by Mass Spectrometry Based on Photocleavable Tag
}

\author{
R. Lemaire ${ }^{\dagger} \#$, J. Stauber ${ }^{\dagger, \#}$, M. Wisztorski ${ }^{\dagger}$, C. Van Camp ${ }^{\dagger}$, A. Desmons ${ }^{\dagger}$, M. Deschamps $^{\ddagger}$, \\ G. Proess $\ddagger$, I. Rudlof $\ddagger$, A. S. Woods $§$, R. Day ${ }^{\|}$, M. Salzet ${ }^{\dagger}$, and I. Fournier ${ }^{\dagger},{ }^{*}$ \\ Laboratoire de Neuroimmunologie des Annélides, FRE CNRS 2933, MALDI Imaging Team, \\ Université des Sciences et Technologies de Lille, 59655 Villeneuve d'Ascq Cedex, France, Société \\ EUROGENTEC, Eurogentec Biologics Department, LIEGE Science Park, Rue Bois Saint-Jean 14, \\ 4102 Seraing, Belgium, NIDA IRP, National Institutes of Health, Baltimore, Maryland 21224, and \\ Département de Pharmacologie, Faculté de médecine, Université de Sherbrooke, Sherbrooke, \\ Québec J1H 5N4, Canada
}

\begin{abstract}
MALDI tissue imaging of tissues has become a promising technique for tracking biomarkers while determining their location and structural characterization. We have now developed specific targeting probes (oligonucleotides, antibodies), named Tag-Mass. This approach is based on probes modified with a photocleavable linker coupled with a tag cleaved and detected using mass spectrometry. TagMass development is the key for a rapid, sensitive, and accurate approach to correlate levels of expression of different mRNA or proteins in diseases.
\end{abstract}

\section{Keywords}

MALDI; specific tissue imaging; Tag-Mass; photocleavage; multiplex; transcriptome; proteome

\section{Introduction}

MALDI imaging is a novel and powerful tool for direct detection and localization of biomolecules. ${ }^{1-6}$ Developments in this field have led to the study and anatomical localization of drugs, lipids, peptides, and proteins in tissue sections. ${ }^{3-8}$ This method eliminates timeconsuming and work-intensive steps such as extraction, prepurification, or separation.

Many successful applications of this technique have been undertaken recently. Of particular interest, the application of MALDI imaging to the direct analysis of diseased tissues to hunt for specific biomarkers. ${ }^{4,9}$

Biological processes include different signaling pathways that involve all different classes of molecules from oligonucleotides, to proteins, peptides, and lipids. In particular, correlation of

\footnotetext{
(C) $\operatorname{xxxx}$ American Chemical Society

* To whom correspondence should be addressed. isabelle.fournier@univ-lille1.fr.

†Université des Sciences et Technologies de Lille.

\#Authors contributed equally.

†Société EUROGENTEC.

$\S_{\text {National Institutes of Health. }}$

"Université de Sherbrooke.
}

Supporting Information Available: Protocols for the peptide/photocleavable linker tagged molecules synthesis and structures of the peptide/photocleavable linker tagged molecules. This material is available free of charge via the Internet at http://pubs.acs.org. 
mRNA with their corresponding protein, or more generally of transcriptome with proteome, is of special interest for better understanding of mechanisms or earlier diagnosis of pathologies. However, some specific classes of biomolecules such as oligonucleotides or sugars are still non or hardly accessible to direct analysis of tissues by MALDI, as are also very hydrophobic proteins, membrane proteins, high mass proteins (>30 kDa), or lower abundance ones..$^{2,4-6,9}$,

${ }^{10}$ Ideally, oligonucleotides should be directly detected from tissues; however, their large size and low abundance in cells, added to analytical difficulties in mass spectrometry ${ }^{11,12}$ because of phosphates groups that lead to extensive salt adducts and high instability of species in the gas phase, render this impossible. If direct detection of mRNA in tissues is not possible, one should find a way for developing indirect detection.

We, thus, proposed a new concept for indirect detection of mRNA that can also be used and extended to other biomolecules. This concept relies on the use of a specific probe design to match a specific target with indirect detection of the probe by mass spectrometry. This concept of indirect detection could be called specific MALDI imaging or "Tag-Mass" concept.

\section{The Tag-Mass Concept: From Indirect Detection of Photocleaved Tags to Images of the Tissue Distributions of mRNAs and Proteins}

The "Tag-Mass" strategy is based on the indirect detection of a probe via a reporter group or "Tag-Mass" indicator added to the probe that is a small molecule of known mass easily detectable by the mean of MALDI mass spectrometry and which is released just before detection step. Here, we designed probes carrying their "Tag-Mass" through a photocleavable linker, chosen to present a specific absorption band in the UV at a wavelength $(340 \mathrm{~nm})$ very closed to that of MALDI lasers (i.e., 337-355 nm). Thus, the analysis of the probe-Tag-mass system results in the release of the tag molecule through laser irradiation and classical detection by MALDI (Figure 1A). Tagged photocleavable linkers can be chemically attached to different classes of probes such as DNA, cDNA, single stranded cRNA, or antibody probes. They can then be used in conjunction with classical tissue-specific molecular targeting using either hybridization methods for oligonucleotides with In Situ Hybridization ${ }^{13}$ (ISH) or paratopeepitope interaction with immuhistochemistry (IHC) approach for antibody probes. ${ }^{14}$

In MALDI, material ejection is promoted by laser irradiation and restricted to the area where the laser beam impacts the sample surface. The mass spectrum reflects the molecular composition of the tissue in this specific site. In the case of mRNA, if the tagged oligonucleotide probe hybridizes to its complementary mRNA sequences, then laser irradiation will photocleave the linker, inducing tag release and leading to the characteristic signal of the tag in the resulting mass spectrum. At positions where no target mRNA are present, the characteristic signal for the tag will not be observed since no hybridization had occurred. Thus, as in standard MALDI imaging, scanning the tissue section in a point-to-point mode, we can obtain images of mRNAs indirectly by reconstructing the molecular image of the tag molecule on the basis of its mass signal mass data (Figure 1B). The same strategy can be adapted for mapping target proteins using tagged antibodies in combination with IHC experiments. For antibodies, preference was given to use indirect IHC with a primary-secondary antibody system. Indeed, indirect IHC is known to present better performances by decreasing steric obstruction problems and increasing detection level, since secondary antibodies will recognize consensus epitope present in the primary antibody sequence allowing attachment of several secondary antibodies. Moreover, secondary antibodies are easier to produce since they require much less specificity. Thus, by chemically modifying secondary antibodies by adding a photocleavable linker and a tag, image reconstruction on the base of tag signal give the studied protein image.

Here, we report the proof that such a new concept can work, with good sensitivity, both for mRNA and proteins using a peptide as tag molecule. 
A specific tagged antibody can be used for indirect experiments. However, in our opinion, addition of the linker and tag on a secondary antibody recognizing the C-terminus of a primary antibody is easier to use and allows signal amplification. Thus, as for ICC experiments, a primary antibody will specifically bind its target antigen. The tagged secondary antibody will then specifically recognize the first one Then, as for mRNA, the scanning of the tissue sections using MALDI MS will allow indirect detection of the protein by monitoring the tag in the mass spectra. As for oligonucleotides, multiple different protein-specific images can be obtained by MALDI in one experiment by using directly tagged primary antibodies with different peptides or secondary antibodies developed in different animal species.

Inherent in this approach to specific molecular imaging of mRNA and proteins are the sensitivity and multiplex possibilities of mass spectrometry. It should be of great interest for transcriptome/proteome co-localization mapping, and will find application when and where co-locating a protein and its corresponding mRNA are important. It should give evidences of the heterogeneity of distribution of localized transcriptional regulation of a specific transcript compared to its corresponding protein level.

\section{Materials and Methods}

a-Cyano-4-hydroxycinnamic acid (HCCA), 3-hydroxypicolinic acid (3-HPA), angiotensin II, Des-Arg-bradykinin, substance P, ACTH 18-39, ACTH 7-38, and bovine insulin were obtained from Sigma-Aldrich and used without any further purification. Trifluoroacetic acid (TFA) was purchased from Applied Biosystems. Acetonitrile p.a. and methanol p.a. were from J.T. Baker.

For Tag synthesis, solvents (DMF, dichloromethane) purchased from Biosolve were of the peptide synthesis grade and used as they were. The amino acids and the 4-[4-[1-(Fmoc-amino) ethyl]-2methoxy-5-nitrophenoxy]butanoic acid (photo-clivable linker) were purchased from Novabiochem; the $N$-methylmorpholine (NMM), the $N, N^{\prime}$-diisopropylcarbodiimide (DIPCD), $N$-(3-dimethylaminopropyl)- $N N^{\prime}$-ethylcarbodiimide hydrochloride (EDAC), and the $N, N$ diisopropylethylamine (DIPEA) from Aldrich; the trifluoroacetic acid and the 2-(1Hbenzotriazole 1-yl)-1,1,3,3-tetramethyluronium tetrafluoroborate/ $N$-hydroxybenzotriazole (TBTU) from Biosolve; the goat anti-rabbit IgG and the PD 10 (G 25 resin column) from Sigma; and the 3-maleimidobenzoic acid $N$-hydroxysuccinimide ester (MBS) from Pierce.

\section{Peptide Tagged Photocleavable Molecules Synthesis}

1. Photocleavable Tagged Oligonucleotide-The peptide is synthesized on Symphony (Protein Technologies, Inc.) and purified on a Delta-Pak C18, $15 \mu \mathrm{m}, 100$ A column (Waters). The oligonucleotide is synthesized from 3' to 5' on Expedite (Applied BioSystem). The amine function with photocleavable linker is added in the $5^{\prime}$ region before cleavage and deprotection. These steps are performed using a $28 \% \mathrm{NH}_{4} \mathrm{OH}$ solution during $24 \mathrm{~h}$ in the dark. The amino oligonucleotide is then purified on a Delta-Pak C18, $15 \mu \mathrm{m}, 300 \AA$ A column (Waters). The amino function of the oligonucleotide is coupled with a heterobifunctional reagent comprising a maleimide function. The maleimido oligonucleotide is solubilized in water and added to a 1.2 equiv of peptide in solution. The mixture is stirred for $16 \mathrm{~h}$. The oligo-peptide conjugate is then purified on a Delta-Pak C18, $15 \mu \mathrm{m}, 300 \AA$ column (Waters) and characterized using MALDI-MS (see Mass Spectrometry section).

2. Photocleavable Tagged Antibody-Peptides were custom-made by Eurogentec S.A. using solid-phase peptide synthesis (SPPS) on a 0.25 mmol scale using Fmoc (9fluorenylmethyloxycarbonyl amino-terminus protection) standard synthesis protocols (4 equiv of Fmoc-AA) with double coupling reactions (twice $40 \mathrm{~min}$ ) using TBTU/NMM which has activator on a Symphony (Rainin Instrument Co., Woburn, MA) synthesizer. The photocleavable linker (4 equiv) was introduced manually using DIPCDI/DIPEA ( $2 \mathrm{~h}$ ) as 
activator. Purifications were performed by RP-HPLC on a Waters (Milford, MA) Delta-Pak $\mathrm{C} 18$ [15 $\mu \mathrm{m}, 100 \AA, 25 \mathrm{~mm} \times 100 \mathrm{~mm}]$ column using a Waters liquid chromatography system consisting of Model 600 solvent delivery pump, a Rheodine injector, and a automated gradient controller (Solvent A, $\mathrm{H}_{2} \mathrm{O} / 0.125 \%$ TFA; Solvent B, CH3CN/0.1\% TFA, Gradients, 5-15\% to $30-60 \%$ B in 20 min). Detection was carried out using Model M2487 variable wavelenght UV detector connected to the Waters Millenium software control unit. The Quality Control was performed by analytical RP-HPLC on a Waters Delta-Pak C18 [5 $\mu \mathrm{m}, 100 \AA, 150 \mathrm{~mm} \times 3.9$ $\mathrm{mm}$ ] column (Solvent A, $\mathrm{H}_{2} \mathrm{O} / 0.125 \%$ TFA; Solvent B, CH3CN/0.1\% TFA. Gradient, $100 \%$ A to $60 \%$ B in $20 \mathrm{~min}$ ) using a Waters Alliance 2690 Separation Module equipped with a Waters 996 Photodiode Array Detector and a MALDI-TOF MS (see Mass Spectrometry section).

The functionalization with the photolinker-derivatized peptide A was done as follows: a solution of $0.5 \mathrm{mg}$ of MBS in $300 \mu \mathrm{L}$ of DMF was added to a solution of $4 \mathrm{mg}$ of goat antirabbit IgG in $2 \mathrm{~mL}$ of PBS and mixed for $30 \mathrm{~min}$. The solution was then desalted on a PD 10 column using $50 \mathrm{mM}$ phosphate buffer at $\mathrm{pH}$. To this desalted activated IgG, a solution of 1 $\mathrm{mg}$ of the photocleavable-derivatized peptide in $300 \mu \mathrm{L}$ of DMF and $1 \mathrm{~mL}$ of PBS was added and stirred for $3 \mathrm{~h}$ at room temperature. Afterward, the reaction mixture was dialyzed overnight against PBS (membrane cutoff 12-14 000).

\section{Synthesis of dUTP-Peptide Conjugates with a Photocleavable Linker-To} prepare this triphosphate, an Fmoc-protected CPG resin was required. The succinylate was prepared from GT115A (100 mg). The sample was relatively pure but contained a small amount (by TLC) of a higher running nontritylated compound. Since it was not possible to purify the succinate, the reaction was modified slightly. 1.5 equiv were used since the exact purity of the product was undetermined. The reaction did not go to completion (from TLC this was more than $50 \%$ ) by comparing the intensity of the components on the TLC by UV (254 nm) and the intensity of the DMT cation upon treatment with $\mathrm{HCl}$ fumes. Since the nonsuccinylated product would not react, the resin was functionalized using this mixture. The resin was prepared, but the loading was very low, $5.4 \mu \mathrm{mol} \mathrm{g}^{-1}$ (180 mg).

The resin was detritylated using 2\% TCA/DCM washed with DCM until the DMT cation was totally removed. This was then dried (argon), and the resin was soaked in pyr/DMF 1:3 (0.4 $\mathrm{mL}$ ) for $5 \mathrm{~min}$ before a solution of $0.1 \mathrm{M}$ Eckstein's reagent in dioxane was added $(0.1 \mathrm{~mL})$. The reaction was allowed to stand for $15 \mathrm{~min}$. The resin was then washed (dioxane, MeCN) and dried (argon). The resin was again soaked in a solution of $0.5 \mathrm{M}$ bis-(tributylammonium) pyrophosphate in anhydrous DMF and tri- $n$-butylamine for $20 \mathrm{~min}$, and the resin was washed (DMF, MeCN) and dried (argon). The product was oxidized (iodine/water/pyridine/THF for $30 \mathrm{~min}$ ), washed (MeCN), and dried (argon). The Fmoc protecting group was removed (20\% piperidine/DMF, $0.5 \mathrm{~mL}, 20 \mathrm{~min}$ ), and the resin was washed thoroughly, (DMF, MeCN) and dried (rgon). This was then washed with DCI, a solution of DCI/photolabile amino linker CEP $(1: 1,0.5 \mathrm{~mL})$ was added, and the reaction was allowed to stand for $20 \mathrm{~min}$. The solution was removed, and the resin washed $(\mathrm{MeCN})$ and dried (argon). A mixture of cap A/cap B (1:1, 0.5 $\mathrm{mL}$ ) was added, and the resin was soaked for $5 \mathrm{~min}$ before removing the capping reagents and washing and drying the resin as before. The product was oxidized $\left(\mathrm{I}_{2} / \mathrm{THF} / \mathrm{pyr} / \mathrm{H}_{2} \mathrm{O}, 5 \mathrm{~min}\right)$, and the resin was washed and dried as before. This was cleaved from the resin with $\mathrm{cNH}_{4} \mathrm{OH}$ at room temperature for $30 \mathrm{~min}$, then purified by anion exchange HPLC on a Dionex NucleoPac100 HPLC column using the following solvent system: Buffer A, $0.1 \mathrm{M} \mathrm{NH}_{4} \mathrm{Cl}$ with $10 \%$ acetonitrile; Buffer $\mathrm{B}, 1 \mathrm{M} \mathrm{NH}_{4} \mathrm{Cl}$ with $10 \%$ acetonitrile; flow rate $2.5 \mathrm{~mL} / \mathrm{min}$ using 6Triphos.mth. This gave 3 fractions (A, $7 \mathrm{~min}$; B, $7.9 \mathrm{~min}$; and C, $10.3 \mathrm{~min}$ ). All 3 fractions were lyophilized overnight before being desalted by reverse-phase HPLC Buffer A, Water; Buffer B, acetonitrile; flow rate $4 \mathrm{~mL} / \mathrm{min}$. The 3 fractions were again lyophilized overnight before being suspended in $200 \mu \mathrm{L}$ of water. MS showed that CMM661A pk 1 was definitely 
not the triphosphate, but it could be either CMM661pk 2 or 3 (very similar MS profiles). (CMM662A was formed from CMM661A pk 2, and CMM663A was formed from CMM661A pk 3.) Both samples were then used in the subsequent reaction. Bicarbonate buffer $(10 \mu \mathrm{L})$ and the maleimide NHS ester $(50 \mu \mathrm{L})$ were added to each sample and the reactions agitated overnight. The samples were diluted with milliQ water $(500 \mu \mathrm{L})$ and filtered. The samples were purified by RP-HPLC, buffer A, 0.1M TEAA; buffer B, MeCN; flow rate $4 \mathrm{~mL} / \mathrm{min}$ using MeCN50.mth and the coupling of the peptide was carried out on these fractions.

\section{Tissue Preparation for in Situ Hybridization (ISH)}

Formalin Fixed Paraffin Embedded tissues (FFPE) sections of $10 \mu \mathrm{m}$ were transferred onto a conductive ITO-glass. Sections were stored at $30{ }^{\circ} \mathrm{C}$ overnight for good adherence. Tissues were then dewaxed using xylene $(2 \times 15 \mathrm{~min})$, and then hydrated during $5 \mathrm{~min}$ in 3 steps of mixed ethanol/water baths $\left(96^{\circ}, 70^{\circ}, 30^{\circ}\right)$. Sections were prepared according to classical ISH protocols. Tissues were incubated in glycine $0.1 \mathrm{M} /$ Tris $\mathrm{HCl}$ buffer $(\mathrm{pH} 7.4)$, then treated for 15 min with proteinase $\mathrm{K}$ for protein digestion $(1 \mu \mathrm{g} / \mu \mathrm{L}$ in $1 \mathrm{M} / \mathrm{Tris} \mathrm{HCl}$ and $0.5 \mathrm{M}$ EDTA, $\mathrm{pH}$ 8). After post-fixation with $4 \%$ paraformaldehyde ( $0.1 \mathrm{M}$ Phosphate $/ 5 \mathrm{mM} \mathrm{MgCl}_{2}$ buffer, $\mathrm{pH} 7.4)$ for $15 \mathrm{~min}$, a 10 min bath with triethanolamine $(0.1 \mathrm{M}, \mathrm{pH} 8)$ was carried out. Sections were washed with $2 \times \mathrm{SSC}$, then ultrapure water for $5 \mathrm{~min}$. Probes were denaturated at $100{ }^{\circ} \mathrm{C}$ for $10 \mathrm{~min}$, and after a 3 step tissue dehydratation $\left(30^{\circ}, 70^{\circ}, 96^{\circ}\right)$, hybridization was done for $16 \mathrm{~h}$ at $55^{\circ} \mathrm{C}$ dissolving cDNA probes in hybridization buffer (Dextran sulfate $10 \%$, formamide $50 \%, 20 \times$ SSC 20\%, 100× Denhardt's 10\%). Tissues were incubated with Rnase $(10 \mu \mathrm{g} / \mathrm{mL}$, $\left.37^{\circ} \mathrm{C}, 30 \mathrm{~min}\right)$, then rinced $10 \mathrm{~min}$ with successive SSC/2-mercaptoethanol (0.07\%) solutions $(2 \times, 1 \times)$, and twice $0.5 \times$ at $55^{\circ} \mathrm{C}$ for $30 \mathrm{~min}$. After rinsing slices with $0.1 \times \mathrm{SSC}$ for $5 \mathrm{~min}$ at room temperature, one bath of ultrapure water was carried out to remove the excess of polymers. Tissues were kept drying at room temperature before MALDI matrix application.

\section{Tissue Preparation for Immunocytochemistry (ICC)}

Adult male Wistar rats weighing 250-350 g (animal welfare accreditation by the French ministry of the agriculture No. 04860) maintained under standard care were used. Animals were sacrificed by decapitation and immediately dissected to remove the brain. Frozen sections of $10 \mu \mathrm{m}$ were performed on a cryostat and immediately transferred onto a conductive IndiumTin Oxide (ITO) glass (Bruker Daltonics, Wissenbourg, France). After drying sections for 5 $\mathrm{min}$ at room temperature, tissues were heated at $80^{\circ} \mathrm{C}$ for $20 \mathrm{~s}$ to allow for good adherence on slides. Rat brain sections were incubated at room temperature with $500 \mu \mathrm{L}$ of buffer $(0.1 \mathrm{M}$ PBS $/ 1 \%$ BSA $1 \%$ normal goat serum/0.05\% Triton X100) for 30 min. The same buffer was used to dilute carboxypeptisase D (CPD) antibody (1:400), and incubation was performed overnight at $4{ }^{\circ} \mathrm{C}$. After washing 3 times in PBS, sections were incubated with peroxidaseconjugated secondary antibody (anti-rabbit IgG 1:100 developed in goat; Jackson Immunoresearch, Inc., Europe LTD) or FITC-conjugated secondary antibody (anti-rabbit IgG 1:100 developed in goat; Jackson Immunoresearch, Inc., Europe LTD) or using photocleavable tagged antibody (1:100) for $80 \mathrm{~min}$ at room temperature. After another 3 washing steps in PBS buffer, the sections for peroxydase ICC were incubated in chloronaphtol with $0.05 \% \mathrm{H}_{2} \mathrm{O}_{2}$ for detection. Reaction was stopped with several PBS and ultrapure water baths. For FITC ICC, slices were prepared using phenylenediamine in glycerol. For photocleavable tagged antibody, tissues were rinced 3 times for 5 min with ultrapure water to remove salts, and sections were kept drying at room temperature before matrix application. Tissues were then compared using microscopy. 


\section{Mass Spectrometry}

1. Sample Preparation for MALDI-MS Analysis-For classical analysis, $1 \mu \mathrm{L}$ of sample solution and $1 \mu \mathrm{L}$ of matrix solution were mixed on the MALDI plate using the dried-droplet technique.

2. Classical Analysis in Linear Mode-Acquisition parameters were set to acceleration voltage, $20 \mathrm{kV}$; first grid voltage, 94\%; guide-wire voltage, $0.05 \%$; extraction delay time, 200 ns.

Each spectrum was the average of 100 laser shots.

3. MALDI-MS Direct Analysis and MALDI Imaging-MALDI-TOF mass spectra and imaging were performed on a Voyager-DE STR mass spectrometer (Applied Biosystems, Framingham, MA) with delayed extraction (DE) and a $337 \mathrm{~nm}$ pulsed nitrogen laser. For routine analysis, $\mathrm{HCCA}$ was used at concentrations of $10 \mathrm{mg} / \mathrm{mL}$ in $\mathrm{ACN} / \mathrm{H}_{2} \mathrm{O}(2: 1, \mathrm{v} / \mathrm{v}, 0.1 \%$ TFA), and $3 \mathrm{HPA}$ at $50 \mathrm{mg} / \mathrm{mL}$ in $\mathrm{H}_{2} 0 /$ ammonium citrate $(100 \mathrm{mM})$. For direct tissue analysis and MALDI imaging, HCCA was used at $10 \mathrm{mg} / \mathrm{mL}$ in $\mathrm{ACN} / \mathrm{H}_{2} \mathrm{O}(2: 1, \mathrm{v} / \mathrm{v})$. Matrix was applied onto the tissue using a micropipette (typically $20 \mu \mathrm{L}$ for a whole rat brain slice) and then dried at room temperature. External calibration was performed using a peptide mixture (1.6 $\mu \mathrm{M}$ bradykinin, $1.6 \mu \mathrm{M}$ substance $\mathrm{P}, 1.6 \mu \mathrm{M}$ ACTH 18-39, $3.2 \mu \mathrm{M}$ ACTH 7-38, $4.8 \mu \mathrm{M}$ bovine insulin, and $4.8 \mu \mathrm{M}$ bovine ubiquitin in $\mathrm{H}_{2} \mathrm{O}$ ). Slices were visualized in the mass spectrometer using a color CCD camera (SONY). Each recorded mass spectrum is the result of the average of 100 laser shots on the area of interest. Acquisition parameters were set as follow: acceleration voltage, $25 \mathrm{kV}$; first grid voltage, $94 \%$; guide-wire voltage, $0.1 \%$; extraction delay time, $200 \mathrm{~ns}$. Images were reconstructed using MALDI Imaging Tools (MIT, M. Stoeckli, Novartis, Inc., Switzerland). In total, 30000 points covering the whole slice with 100 laser shots per position were scanned. From each position, the software measures an average mass spectrum with its coordinates on the slice.

\section{Results}

\section{Photocleavable Tagged Oligonucleotide Probes: mRNA MALDI Imaging}

To evaluate the performances of photodissociation under UV-MALDI, several oligopeptides (20-mers oligonucleotides) presenting a photocleavable moiety were tested. Photodissociation was assumed to induce cleavage directly between the phosphate group and the photoactivable linker ${ }^{15}$ (see supplementary data, structure 1, Supporting Information). As shown in Figure 2, photocleavage by laser irradiation is efficient and results in the characteristic signal expected for the $\operatorname{tag}(\mathrm{m} / z 1626.37$ noted P-PC). However, the MALDI mass spectrum clearly shows that $100 \%$ photocleavage yield is not achieved, since signals corresponding to the whole intact structure are still observed $\left(\mathrm{m} / z 6970.50\right.$ for $\mathrm{MH}^{+}$ion and 3489.92 for $\mathrm{MH}_{2}{ }^{2+}$ ion). Signals at $\mathrm{m} / \mathrm{z} 5351.03$ and 2678.79 correspond, respectively, to the $\mathrm{MH}^{+}$and $\mathrm{MH}^{2+}{ }_{2}$ of the oligophosphate after photocleavage. Peak broadening from salt adducts and metastable fragmentations decreases mass accuracy, a common occurrence in MALDI oligonucleotide measurements. At $m / z$ 1163.9, the low-abundance peak was attributed to a fast cleavage in the gas phase of the linker disulfide bridge liberating the peptide. To study the possibility of using photocleavage under multiplex analysis conditions, a mixture of three oligopeptides corresponding to three different 20-mers oligonucleotides and three different peptides was investigated. As presented in Figure 3, expected characteristic signals of the photodissociation (P-PC) were observed as proved by the presence of peaks at $\mathrm{m} / \mathrm{z}$ 1346.95, 1603.74, and 1891.72. As expected from previous data, fast fragmentation ions were also observed $(\mathrm{m} / \mathrm{z} 1161.87$, 1449.88) and were especially intense for one of the peptides. For subsequent experiments, 
bradykinin was selected because it gives the best sensitivity (100 fmol) and ease of detection in all analytical conditions (P3).

To increase sensitivity by suppressing fast fragmentation signals, a new photocleavable linker/ tag system was designed replacing the disulfide bridge by a maleimide group for binding the tag peptide to the photocleavable linker (see supplementary data, structure 2, Supporting Information). Studies performed on this structure clearly demonstrate the suppression of fast fragmentation signal and increase of the expected signal for photocleavage. This photocleavable linker/tag system was used to construct double-stranded cDNA oligonucleotidic probes. Proenkephalin was chosen as the model target mRNA because previous studies gave low background for this molecule's mRNA distribution in the rat brain. ${ }^{16}$ Standard untagged and tagged primers bearing the photocleavable linker/tag system were added to the proenkephalin cDNA sequence. Both types of primers were used for RT-PCR amplification and have given the same results in terms of product and yield of amplification. RT-PCR was used to make a 400 bp double-stranded cDNA oligonucleotidic probe (data not shown). The probe was tested in ISH experiments and followed by MALDI analysis of hybridized rat brain tissue sections for tag detection. The mass spectra obtained clearly demonstrated the possibility of detecting the characteristic ion signal for the tag in some specific region of the section hybridized with the tagged probes. This signal was neither found for control tissue sections with the untagged proenkephalin probe nor for the sense control tissue sections. Although signal intensity for the tag was weak, the feasibility of the proposed strategy was unambiguously demonstrated, it was lacking sensitivity. Therefore, the strategy was slightly modified to improve sensitivity, increase specificity, and facilitate usage.

An alternative approach was developed, based on the labeling of a single desoxyribo nucleotide triphosphate (dNTP). For these experiments desoxyribo uracile triphosphate (dUTP) was chosen and chemically modified with the same photocleavable linker/tag system described above (Figure 4b). This new design keeps both the $5^{\prime}$ and $3^{\prime}$ ends of the nucleotide free, allowing the synthesis of riboprobes containing the modified base by in vitro translation. This first step increases the specificity of the method, thus, preventing nonspecific binding to genomic DNA. Moreover, use of a tagged nucleotide leads to the incorporation of one tag for each T nucleotide basis (Figure 4a), increasing sensitivity. Finally, the use of tagged nucleotides has the very practical consequence that these nucleotides can be incorporated using standard procedures, regardless of the probe being amplified. The dUTP-tagged nucleotides were tested for photocleavage, as shown in Figure 5. Again, the characteristic signal of the tag peptide was observed $(\mathrm{m} / \mathrm{z}, 1163.23)$, with very good $\mathrm{S} / \mathrm{N}$ ratio and signal intensity, demonstrating that the maleimide group incorporation prevents fast fragmentation. The dUTP-tagged system was used for amplifying the proenkephalin probe by RT-PCR. As expected from the structure (Figure 4b) and previously described for digoxygenin-tagged uracile (dUTP-DIG) systems, 17 nucleotides ratios had to be optimized, with best results obtained for a ratio 1:3 of tagged dUTP and dTPP (desoxyribo thymine triphosphate). ISH was performed with the multiple tagged proenkephalin amplified probes. MALDI analysis of the hybridized rat brain tissue sections was then carried out and compared to the analysis of adjacent tissue sections hybridized with untagged proenkephalin probe amplified in the same conditions but with unmodified uracile. The characteristic signal of the tag peptide was observed in rat brain tissue for the multiply tagged proenkephalin probe (Figure 6b), whereas this signal never appeared when the untagged probe was used (Figure 6a) or the sense probe used. As expected, mass spectra reveal a clear increase in detection of the ion corresponding to the tag peptide. MALDI imaging was subsequently performed on this tissue section by scanning the tissue and recording corresponding mass spectra (7000 spots, $100 \mu \mathrm{m}$ steps). On the basis of the characteristic tag signal (Figure 6b), an image of the molecular distribution of proenkephalin mRNA was reconstructed, as presented in Figure 6e. The image fits the tissue morphology well (Figure 6f) and matches the proenkephalin mRNA distribution obtained by ISH with autoradiography 18 
or the one obtained in mouse brain with digoxigenin probe ${ }^{19}$ (Figure $6 \mathrm{c}, \mathrm{d}$ ). These experiments clearly demonstrate the feasibility of specific mRNA imaging by MALDI mass spec-trometry.

\section{Photocleavable Tagged Antibody Probes for Antigen MALDI Imaging}

The same concept was applied in obtaining specific images of proteins using tagged secondary antibodies. As previously explained, to gain sensitivity and ease of use, secondary antibodies were tagged on the C-terminal part of their $\mathrm{Fc}$ chain (Figure 7). Immunohistochemsitry (IHC) experiments were performed with a standard primary antibody directed against the protein of interest, and peroxydase or FITC-tagged secondary antibodies were replaced by our specifically modified antibody for MALDI imaging. The tagged antibody was first tested to evaluate the yield of photocleavage and to assess the presence of expected tag signals.

Examination of the mass spectra leads to the observation of two characteristic signals for the $\operatorname{tag}(\mathrm{m} / \mathrm{z}, 1686.43$ and 1703.23$)$. The higher $\mathrm{m} / \mathrm{z}$ signal corresponds to the P-PC moiety observed with the oligonucleotide probes. The $\mathrm{m} / \mathrm{z} 1686.43$ signal corresponds to the same moiety minus one oxygen. Such signals have already been described for photocleavable systems, but no mechanism was proposed. ${ }^{15}$ Two unexpected, less abundant signals were also observed and were attributed to some of the maleimide reaction intermediates remaining in the solution after purification. As for oligonucleotides, photocleavage with antibodies was highly efficient, resulting in the observation of characteristic tag peptide signal. For further experiments, Carboxypeptidase D was chosen as model target protein for several reasons, in particular its presence in some rat brain regions as known from previous studies and the impossibility of its direct detection by MALDI imaging because of its large mass and nature (membrane protein of $180 \mathrm{kDa}) .{ }^{20} \mathrm{IHC}$ experiments were carried out in parallel on three adjacent rat brain sections using the same primary antibody and comparing our tagged antibody to the same but peroxydase or FITC-labeled antibody. As shown in Figures 8a, several signals were observed from the direct analysis of the tissue section with the FITC antibody corresponding to peptides present in the tissue section. The mass spectrum obtained in the same region with the tagged antibody also displays these signals (Figure 8b). However, in this case, two more signals corresponding to the expected signals for the tag peptide were also observed. This tissue section was then kept for MALDI imaging scanning of 30000 spots, in $100 \mu \mathrm{m}$ steps. On the basis of signal intensity for the characteristic ion at $\mathrm{m} / \mathrm{z} 1686.43$, which is the most abundant one, the image was reconstructed, indirectly giving the image of the protein (Figure 8c). As observed in the figure, very good image resolution was obtained. The protein distribution in the section is perfectly correlated to tissue structure, as observed when comparing to a picture of the section before IHC experiments (Figure 8d). The MALDI image was compared to the results obtained for the enzyme-linked secondary antibody using substrates of peroxydase for the revelation by a precipitation reaction. Both substrates DAB (3,3'-diaminobenzidine tetrahydrochloride) and 4-chloronaphtol of peroxydase were investigated, and results obtained with 4-chloronaphtol revelation are presented Figure 8f. Comparison pictures of 4-chloronapthol or DAB labeling with MALDI images based on the tag detection show that CPD protein is detected in the same area of the brain using both methods, thus, validating the methodology. However, in some specific areas, such as the hypocampus, CPD was detected with the tag-mass system, while no signal was detected with the precipitation reaction, indicating that the indirect detection by mass spectrometry is more sensitive than classic techniques. Comparing the MALDI image of CPD with the fluorescence image obtained from the section on which the FITC-linked secondary antibody was used (Figure 8e), MALDI appears to present a good sensitivity. It is worth noting that the MALDI molecular strategy gives a more localized signal compared to fluorescence, which is diffuse and presents a significant amount of background noise due to the natural fluorescence of the tissue. Moreover, at low magnification, signals are found in the same areas by fluorescence and MALDI imaging. These results demonstrate the validity of the strategy for imaging very specific proteins of interest. 


\section{Discussion}

MALDI imaging is an emerging technology that allows the localization and direct identification on tissue sections of biomolecules. The ability to co-localize in some specific area of the tissue different classes of molecules (e.g., mRNA, proteins, peptides, lipids, drugs) is the key for apprehending molecular mechanisms in living systems. Nevertheless, certain biomolecules cannot be directly imaged, leading to loss of information. We have proposed, here, a new concept for allowing their indirect detection, based on tagged photocleavable probes. The strategy was optimized and successfully applied to mRNA and antigens by using, respectively, tagged photocleavable oligonucleotides and secondary antibodies. Actually, the proof of the proposed concept was demonstrated, but several developments still remain. Actually, MALDI has a quite poor lateral resolution ( $75 \mu \mathrm{m}$ pixels) very far from classical optical microscope $(<<1 \mu \mathrm{m})$, but much effort is currently underway to improve the resolution of MALDI images by using more focused laser systems. On the other hand, even if MALDI's first strength is the possibility to detect numerous biomolecules without any background information required, MALDI specific imaging gives access to specific molecules that could never be directly observed. But why use MALDI rather than well-established methods such as radio elements or fluorescence in combination with microscopy? First, MALDI mass spectrometry is a very sensitive method that still could increase its potential by instrumental and fundamental developments. Radioactivity is very sensitive but very difficult to handle and has advantageously been replaced by fluorescence. Fluorescence is extremely sensitive and resolute but has shortcomings such as signal diffusion, high background, cells' autofluorescence or quenching phenomena, and short lifetimes of the signal. In this respect, mass spectrometry can be advantageous. Moreover, one of the great strength of the "Tag-Mass" system compared to fluorescence will be its multiplex capacities. For fluorescence, only a restricted number of fluorophores are useable, whereas in the present strategy, the number of tags is a priori unlimited. The multiplex approach allowing for the simultaneous detection of several mRNA and proteins is currently under investigation. Finally, it has been observed that, in addition to the signal of the tag when analyzing the tissue section, classical signal for peptides and proteins can still be observed. Optimizing the method for obtaining both classical MALDI signal of tissue section and specific image should give a great strength to MALDI imaging.

\section{Conclusion}

We have demonstrated here the application of a new concept for specific imaging of mRNA and proteins, using MALDI mass spectrometry to image target molecules in sectioned tissue. This strategy relies on targeting specific biomolecules with probes that contain a photocleavable linker and a tag moiety that can be photodissociated by MALDI laser irradiation. We have successfully tested this strategy with peptide tags on oligonucloeotide and antibody probes. With this method; we were able to image a $180 \mathrm{kDa}$ membrane protein and proenkephalin mRNA. For oligonucleotides, U-tagged nucleotide probes were found to be the best choice for increased sensitivity and flexibility. Mass spectrometric detection was shown to be very sensitive, yielding distributions of the molecules of interest on whole tissue sections with more sensitivity than most of the classical methods using peroxydase as a substrate, and giving images of molecules that could not be observed directly by MALDI imaging. Such a strategy presents a great potential for multiplex approach and is under investigation. Sensitivity is also tested by optimizing the tag and trying other tag families that could give better signal detection by MALDI. Thus, MALDI matrices or compounds absorbing at the laser wavelength and possibly detectable by Laser Desorption Ionization (LDI) will be investigated to acquire images without the need for the matrix. This strategy can also be extended to other types of probes, including lectins or aptamers, which will also allow for imaging polysaccharides, peptides, proteins, or drugs (Figure 9). 
"Tag-Mass" strategy is a new concept that could bring very useful information, especially to obtain, for example, transciptome/proteome co-localization maps, and could be very interesting in the future for diagnosis of pathologies.

\section{Supplementary Material}

Refer to Web version on PubMed Central for supplementary material.

\section{Acknowledgments}

Supported by grants from Centre National de la Recherche Scientifique (CNRS), Ministère de L'Education Nationale, de L'Enseignement Supérieur et de la Recherche (ACI Jeunes Chercheurs ACI JC4074 to I.F.), Conseil Régional NordPas de Calais to M.W., and the Canadian Institutes of Health Research (CIHR) to R.D. and M.S. Also supported by a collaboration agreement between Bruker Daltonics $\mathrm{GmbH}$ and the Laboratoire de Neuroimmunologie des Annélides. The authors thank Prof. F. Hillenkamp and Prof. E. Macagno for their suggestions.

\section{References}

1. Caprioli RM, Farmer TB, Gile J. Molecular imaging of biological samples: localization of peptides and proteins using MALDI-TOF MS. Anal. Chem 1997;69(23):4751-60. [PubMed: 9406525]

2. Chaurand P, Schwartz SA, Caprioli RM. Profiling and imaging proteins in tissue sections by MS. Anal. Chem 2004;76(5):87A-93A.

3. Fournier I, Day R, Salzet M. Direct analysis of neuropeptides by in situ MALDI-TOF mass spectrometry in the rat brain. Neuroendocrinol. Lett 2003;24(1-2):9-14. [PubMed: 12743525]

4. Rubakhin SS, Jurchen JC, Monroe EB, Sweedler JV. Imaging mass spectrometry: fundamentals and applications to drug discovery. Drug Discovery Today 2005;10(12):823-37. [PubMed: 15970265]

5. Stoeckli M, Chaurand P, Hallahan DE, Caprioli RM. Imaging mass spectrometry: a new technology for the analysis of protein expression in mammalian tissues. Nat. Med 2001;7(4):493-6. [PubMed: 11283679]

6. Caldwell RL, Caprioli RM. Tissue profiling by mass spec-trometry: a review of methodology and applications. Mol. Cell. Proteomics 2005;4(4):394-401. [PubMed: 15677390]

7. Jackson SN, Wang HY, Woods AS. Direct profiling of lipid distribution in brain tissue using MALDITOFMS. Anal. Chem 2005;77(14):4523-7. [PubMed: 16013869]

8. Jackson SN, Wang HY, Woods AS, Ugarov M, Egan T, Schultz JA. Direct tissue analysis of phospholipids in rat brain using MALDI-TOFMS and MALDI-ion mobility-TOFMS. J. Am. Soc. Mass Spectrom 2005;16(2):133-8. [PubMed: 15694763]

9. Rohner TC, Staab D, Stoeckli M. MALDI mass spectrometric imaging of biological tissue sections. Mech. Ageing Dev 2005;126(1):177-85. [PubMed: 15610777]

10. Lemaire R, Tabet JC, Ducoroy P, Hendra JB, Salzet M, Fournier I. Solid ionic matrixes for direct tissue analysis and MALDI imaging. Anal. Chem 2006;78(3):809-19. [PubMed: 16448055]

11. Kirpekar F, Berkenkamp S, Hillenkamp F. Detection of double-stranded DNA by IR-and UV-MALDI mass spectrometry. Anal. Chem 1999;71(13):2334-9. [PubMed: 10405601]

12. Nordhoff E, Kirpekar F, Karas M, Cramer R, Hahner S, Hillenkamp F, Kristiansen K, Roepstroff P, Lezius A. Comparison of IR- and UV-matrix-assisted laser desorption/ionization mass spectrometry of oligodeoxynucleotides. Nucleic Acids Res 1994;22(13):2460-5. [PubMed: 8041606]

13. Qian X, Lloyd RV. Recent developments in signal amplification methods for in situ hybridization. Diagn. Mol. Pathol 2003;12(1):1-13. [PubMed: 12605030]

14. Rossi E, Ubiali A, Cadei M, Balzarini P, Valagussa E, Lucini L, Alpi F, Galletti A, Fontana L, Tedoldi C, Grigolato P. HER-2/neu in breast cancer: a comparative study between histology, immunohistochemistry, and molecular technique (FISH). Appl Immunohistochem. Mol. Morphol 2006;14(2):127-31. [PubMed: 16785778]

15. Olejnik J, Ludemann HC, Krzymanska-Olejnik E, Berkenkamp S, Hillenkamp F, Rothschild KJ. Photocleavable peptide-DNA conjugates: synthesis and applications to DNA analysis using MALDIMS. Nucleic Acids Res 1999;27(23):4626-31. [PubMed: 10556319] 
16. Lansac G, Dong W, Dubois CM, Benlarbi N, Afonso C, Fournier I, Salzet M, Day R.

Lipopolysaccharide mediated regulation of neuroendocrine associated proprotein convertases and neuropeptide precursor processing in the rat spleen. J. Neuroimmunol 2006;171(1-2):57-71.

[PubMed: 16337011]

17. Rees JL, Fisher C. Nonradioactive in situ hybridization with digoxigenin. Trends Genet 1992;8(1): 8. [PubMed: 1285438]

18. Shivers BD, Harlan RE, Romano GJ, Howells RD, Pfaff DW. Cellular localization of proenkephalin mRNA in rat brain: gene expression in the caudate-putamen and cerebellar cortex. Proc. Natl. Acad. Sci. U.S.A 1986;83(16):6221-5. [PubMed: 3461484]

19. Allen brain atlas neuroscience gateway Home page. http://www.brainatlas.org/aba/

20. Dong W, Fricker LD, Day R. Carboxypeptidase D is a potential candidate to carry out redundant processing functions of carboxypeptidase $\mathrm{E}$ based on comparative distribution studies in the rat central nervous system. Neuroscience 1999;89(4):1301-17. [PubMed: 10362316] 


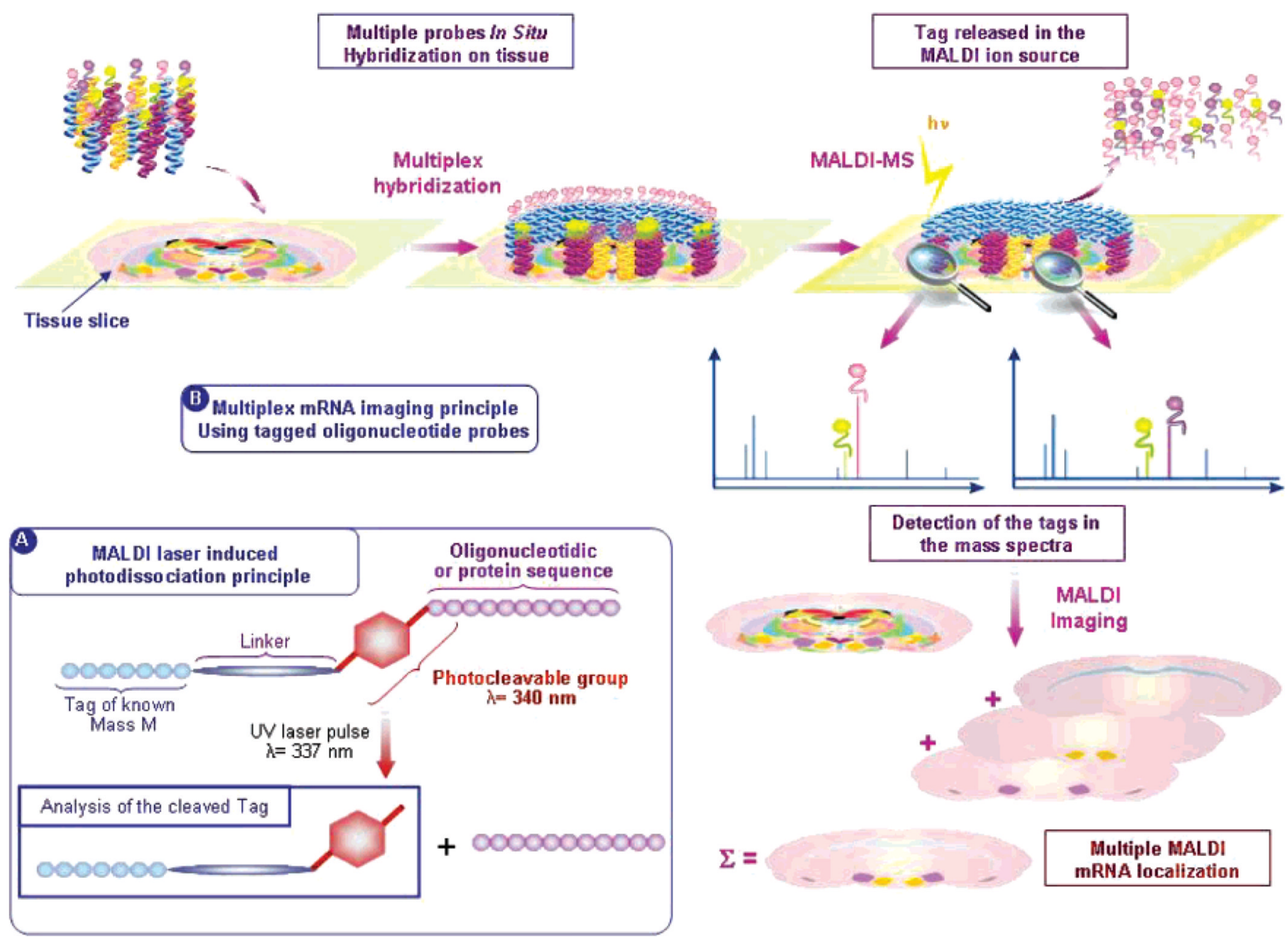

Figure 1.

(A) Schematic representation of the concept of MALDI imaging of mRNA using tagged oligonucleotide probes for detection by photocleavage. (B) Scheme of the photocleavable linker/tag system for indirect detection after photodissociation under the MALDI UV laser wavelength. 


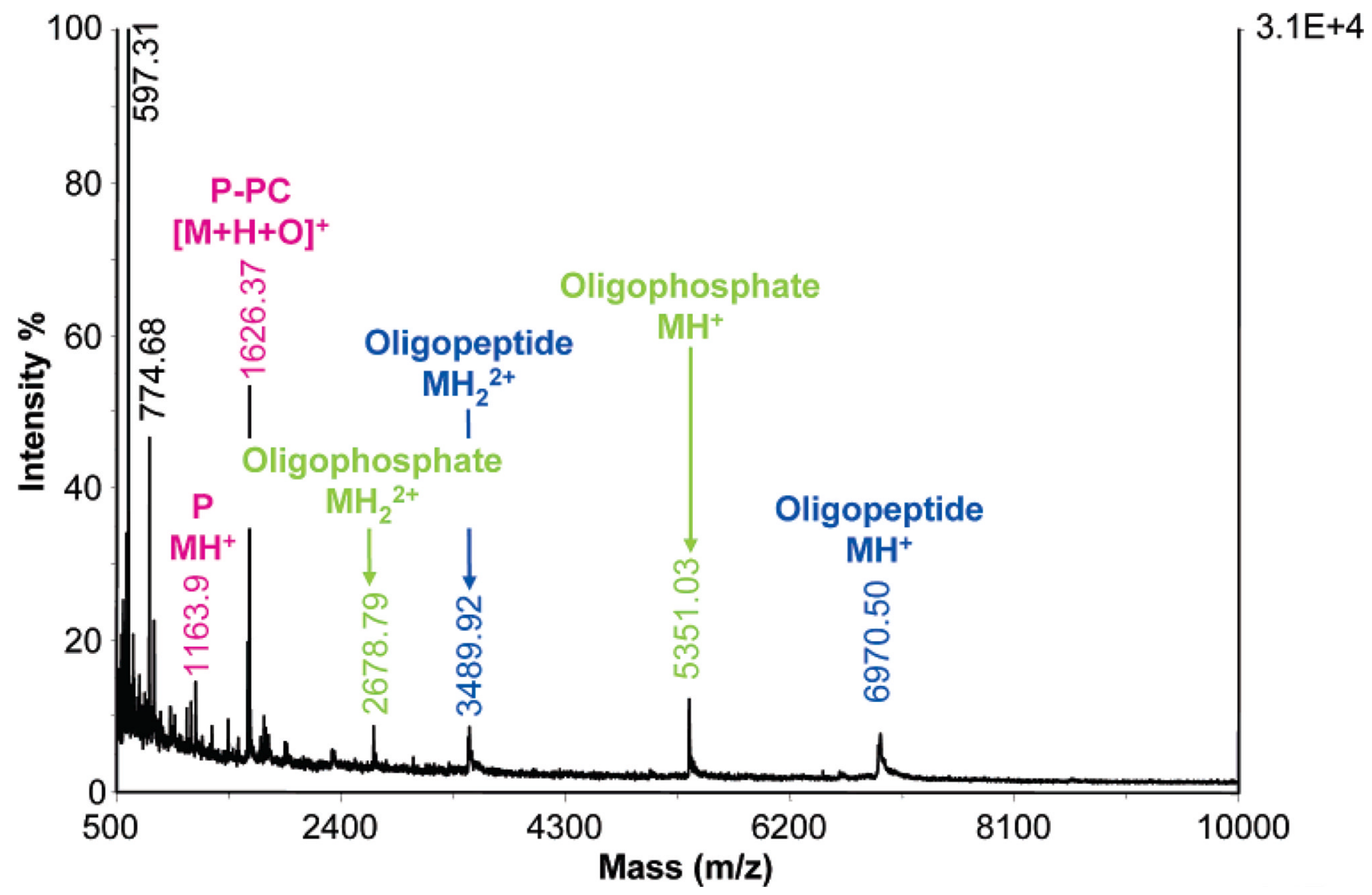

Figure 2.

MALDI mass spectrum in the linear positive mode of an oligopeptide including a 20-mer oligonucleotide sequence and the photocleavable linker/peptide system with 3-HPA as matrix. 


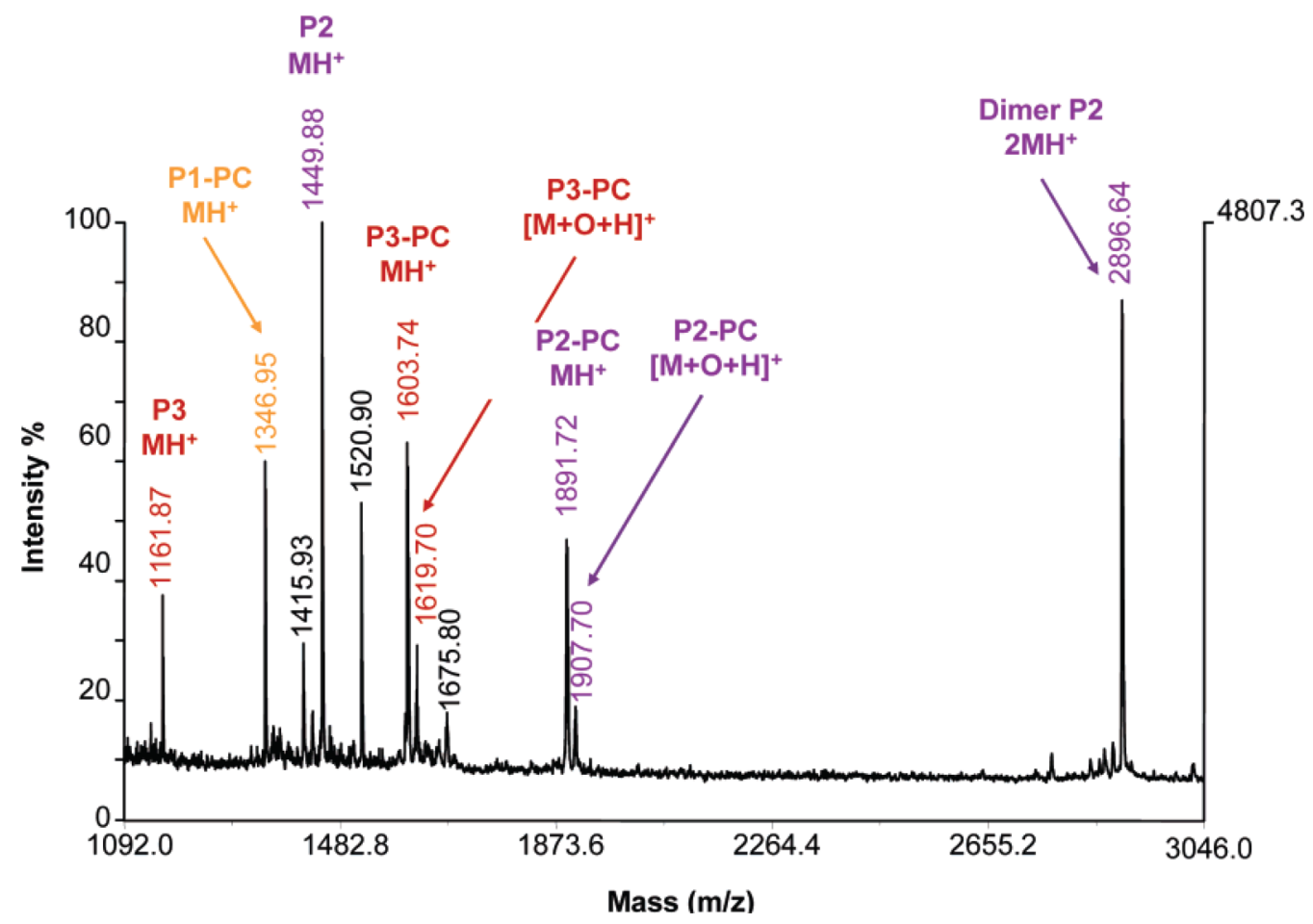

Figure 3.

MALDI mass spectrum in the reflectron positive mode of three oligopeptides including three different 20-mer oligonucleotides and the photocleavable linker/peptide system with three different peptides as tags with HCCA as matrix. 


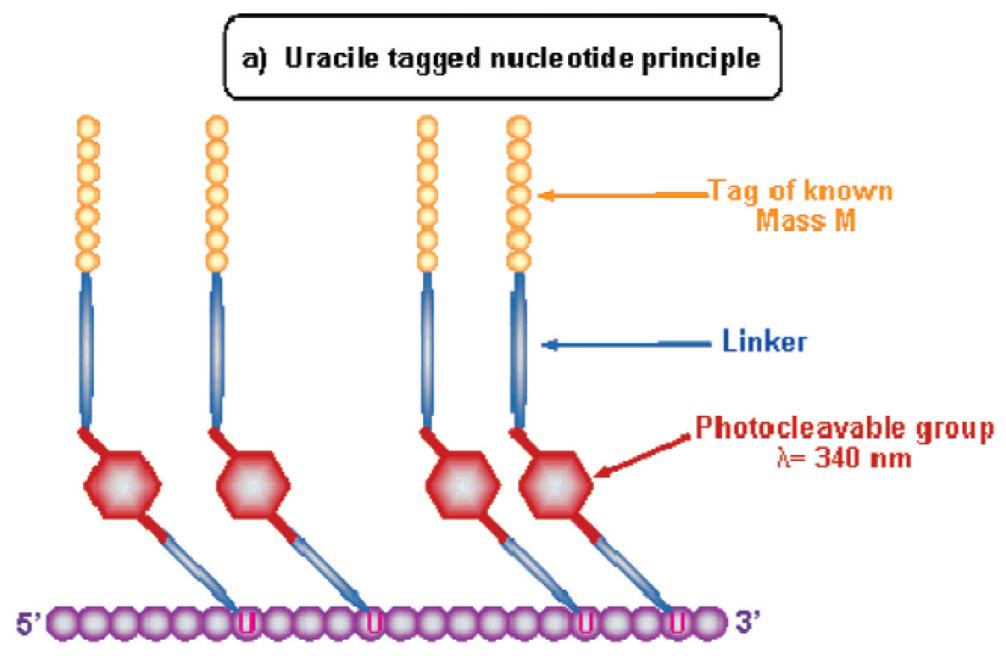

Single strand RN A probe

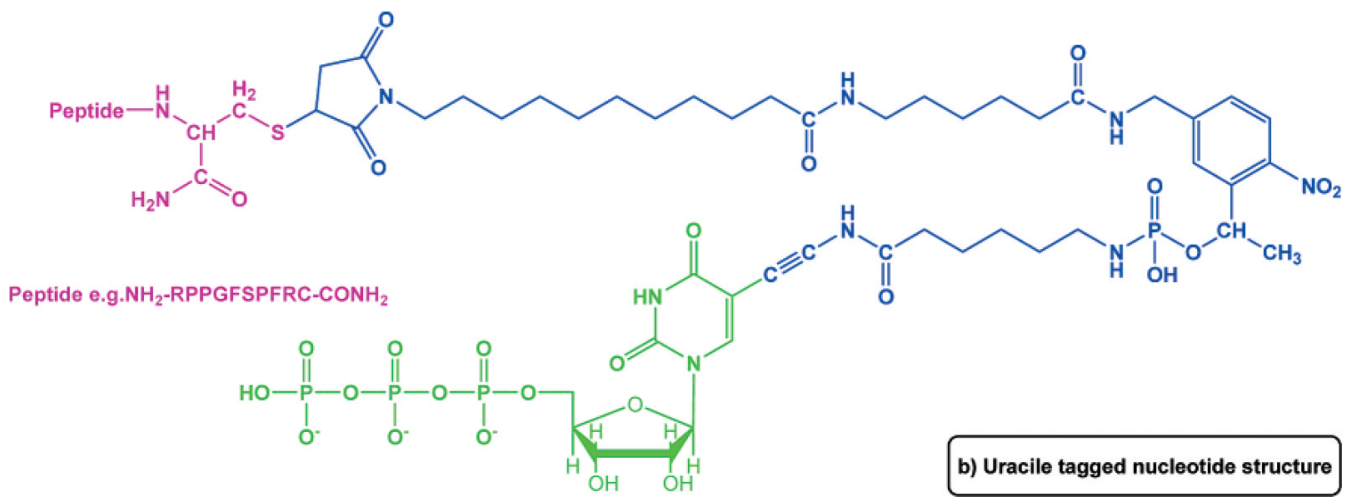

Figure 4.

(a) Schematic representation of the incorporation of the tagged uracile nucleotide in a single strand RNA probe and (b) developed structure of the U-tagged nucleotide. 


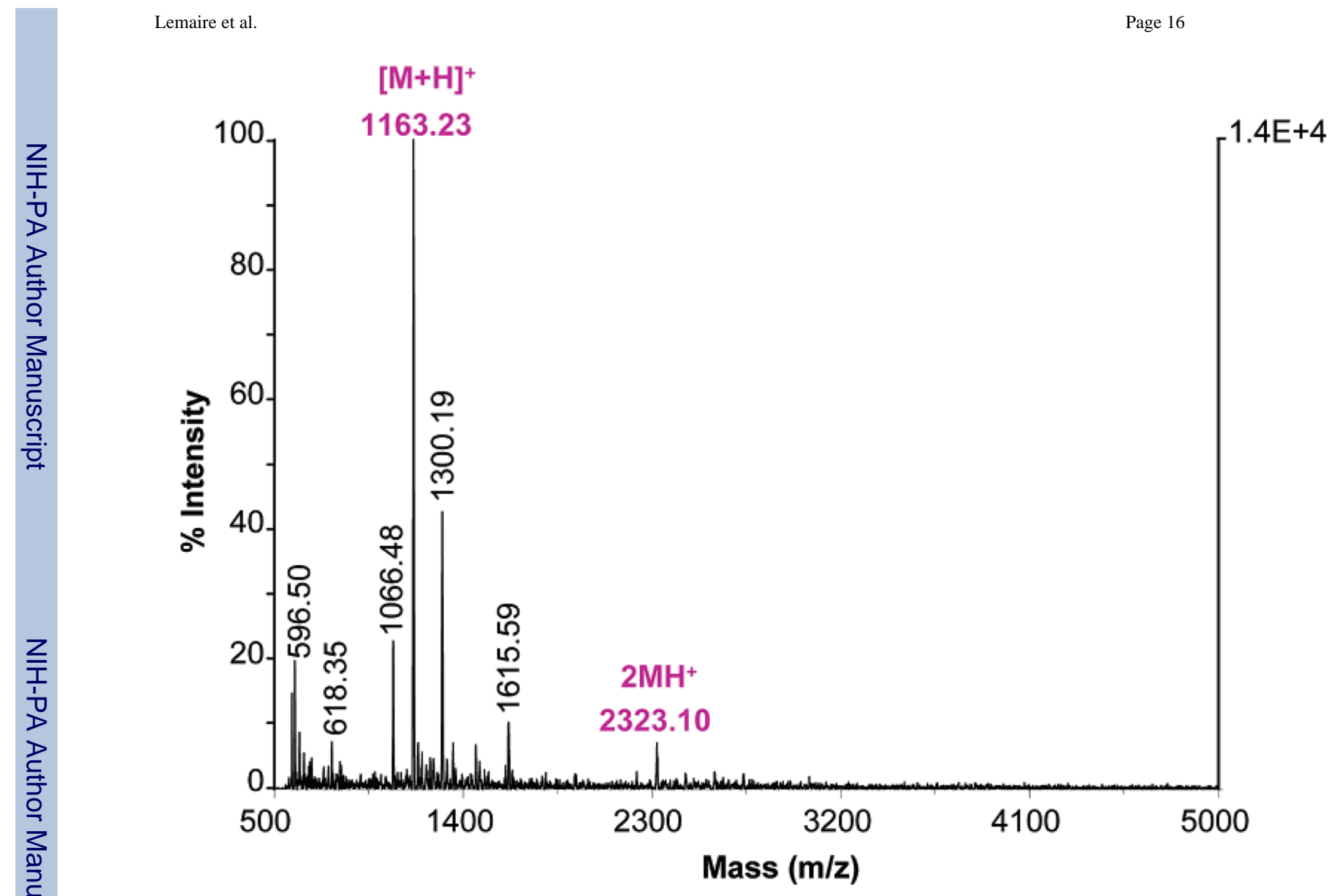

Figure 5.

MALDI mass spectrum in the reflectron positive mode of the U-tagged nucleotide in solution with HCCA as matrix. 

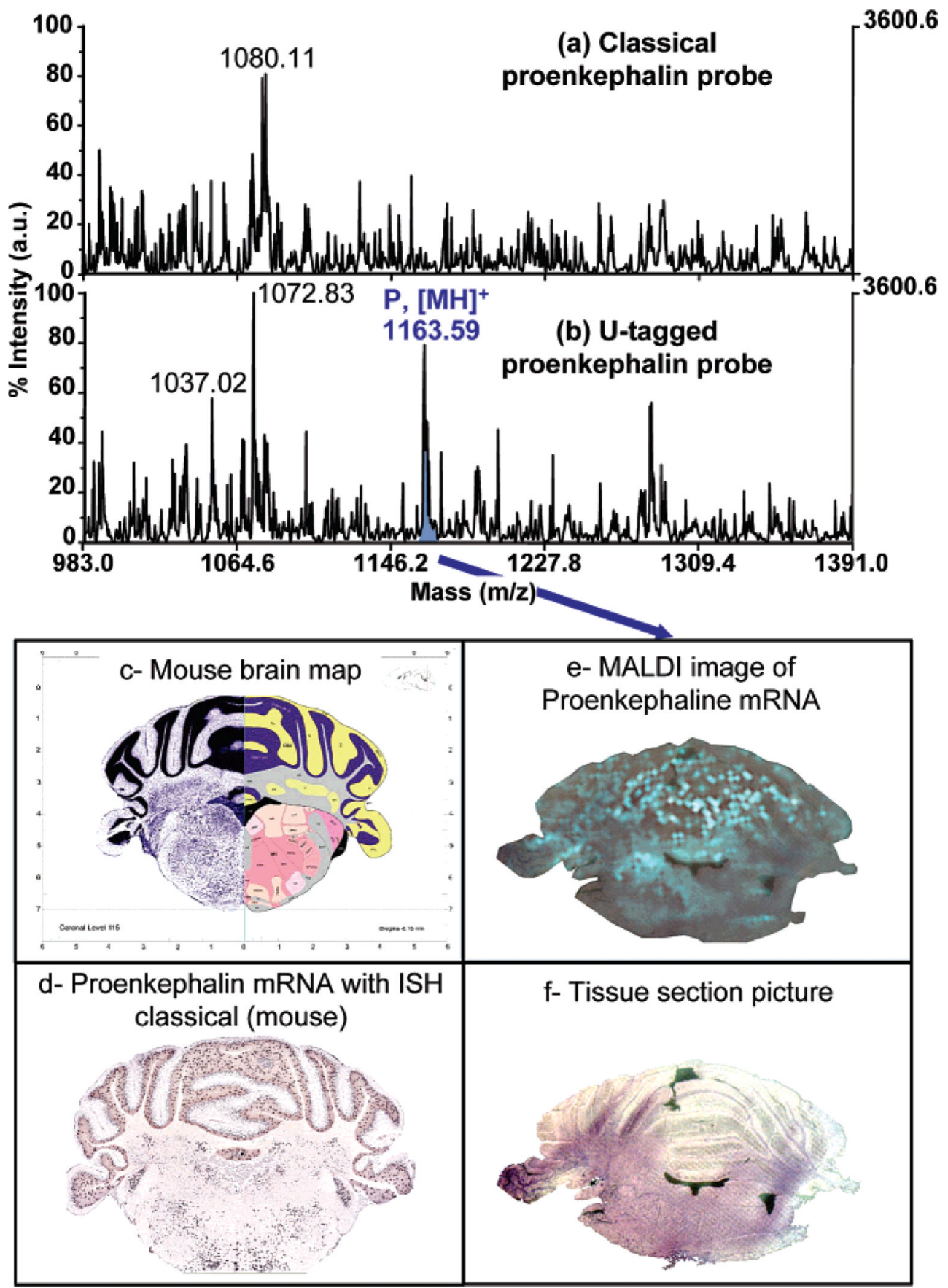

Figure 6.

Comparative MALDI mass spectra in the linear positive mode recorded on two adjacent rat brain sections in the same region of the brain after ISH of double strand oligonucleotide cDNA probe corresponding to proenkephalin for classical untagged proenkephalin probe (a) and the U-tagged proenkephalin probe (b). (f) Corresponding reconstructed MALDI image on the basis of the tag signal obtained by scanning the tissue section after ISH experiment (7000 spots separated each of $100 \mu \mathrm{m}$ ) compared (e) to proenkephalin mRNA localization in 8-week old male C57BL/6J mouse brain using digoxigenin ISH technique by the Allen Institute (http://www.brainatlas.org/aba/). For this experiment, colorimetric detection of bound probe is generated by the alkaline phosphatase substrates nitroblue tetrazolium (NBT) and 5- 
bromo-4-chloro-3-indolyl phosphate (BCIP) that produce a vivid blue/purple particulate reaction product. Figures (c) presents the map/picture representation of the mouse brain and figure (f) the picture of the rat brain section prior to ISH-MALDI imaging experiment. 


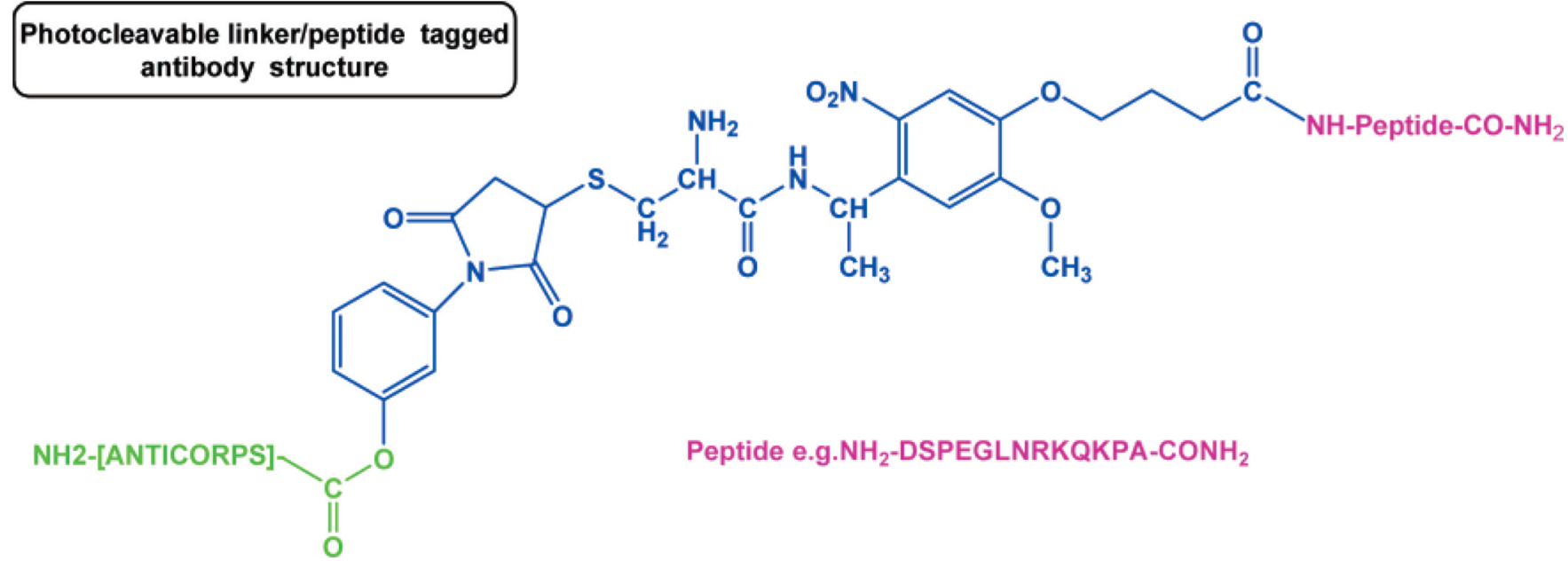

Figure 7.

Developed structure of the photocleavable linker/tag system modified secondary anti-rabbit antibody. 

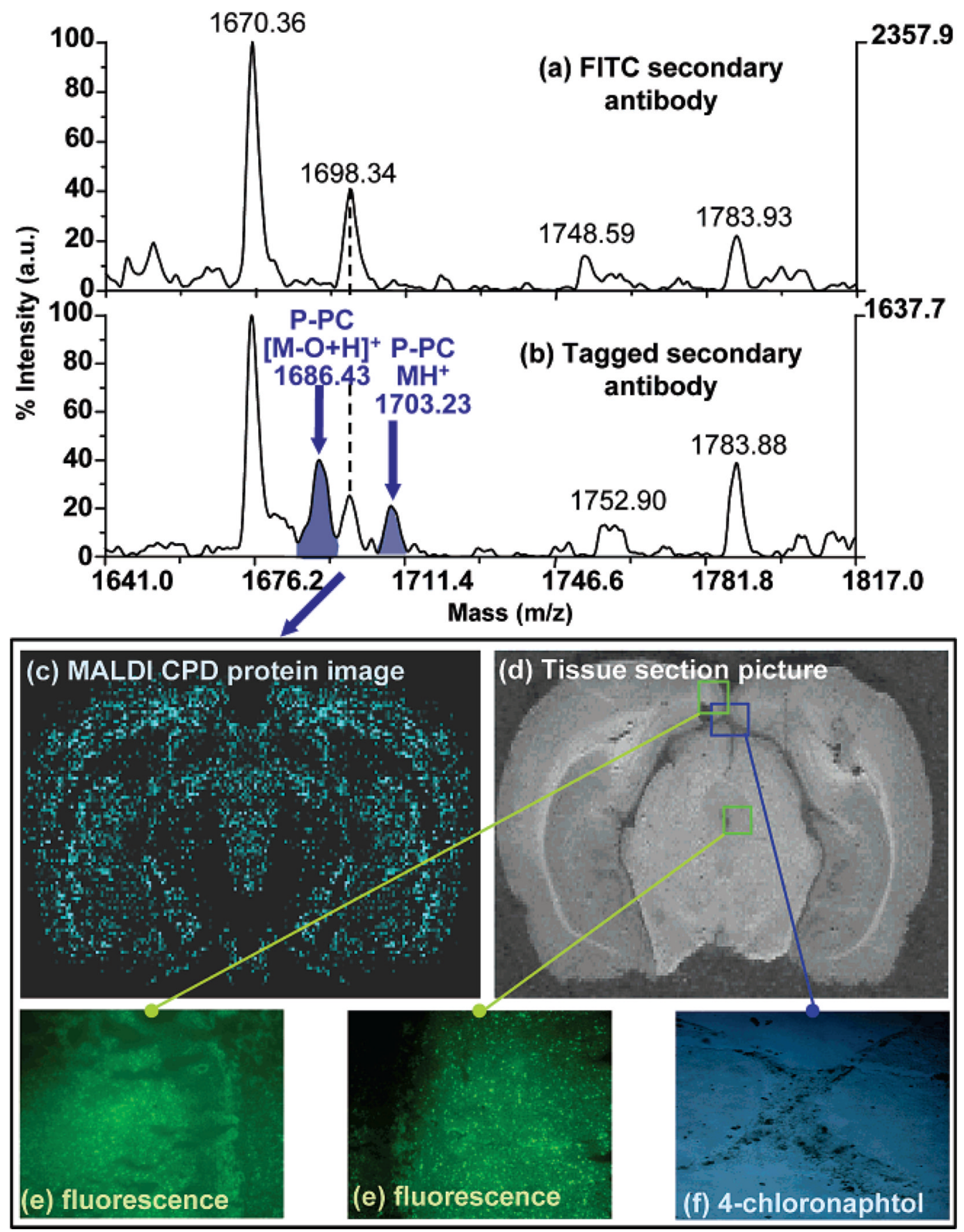

Figure 8.

Comparative MALDI mass spectra in the linear positive mode recorded on two adjacent rat brain sections in the same region of the brain after ICC experiment with a primary antibody directed against carboxypeptidase D protein and an anti-rabbit FITC polyclonal secondary antibody (a) or bearing the photocleavable linker/tag system (b). (c) Corresponding MALDI molecular image reconstructed on the tag peptide characteristic ion screening after ICC experiment with the tagged secondary antibody (30 000 spots separated each of $100 \mu \mathrm{m})$ and (d) rat brain tissue section picture before the ICC experiment. Comparison with pictures of specific region of the adjacent rat brain sections after ICC experiment with FITC labeled 
secondary antibody and fluorescence detection (e) or peroxydase labeled secondary antibody and revelation with 4-chloronaphtol (f). 


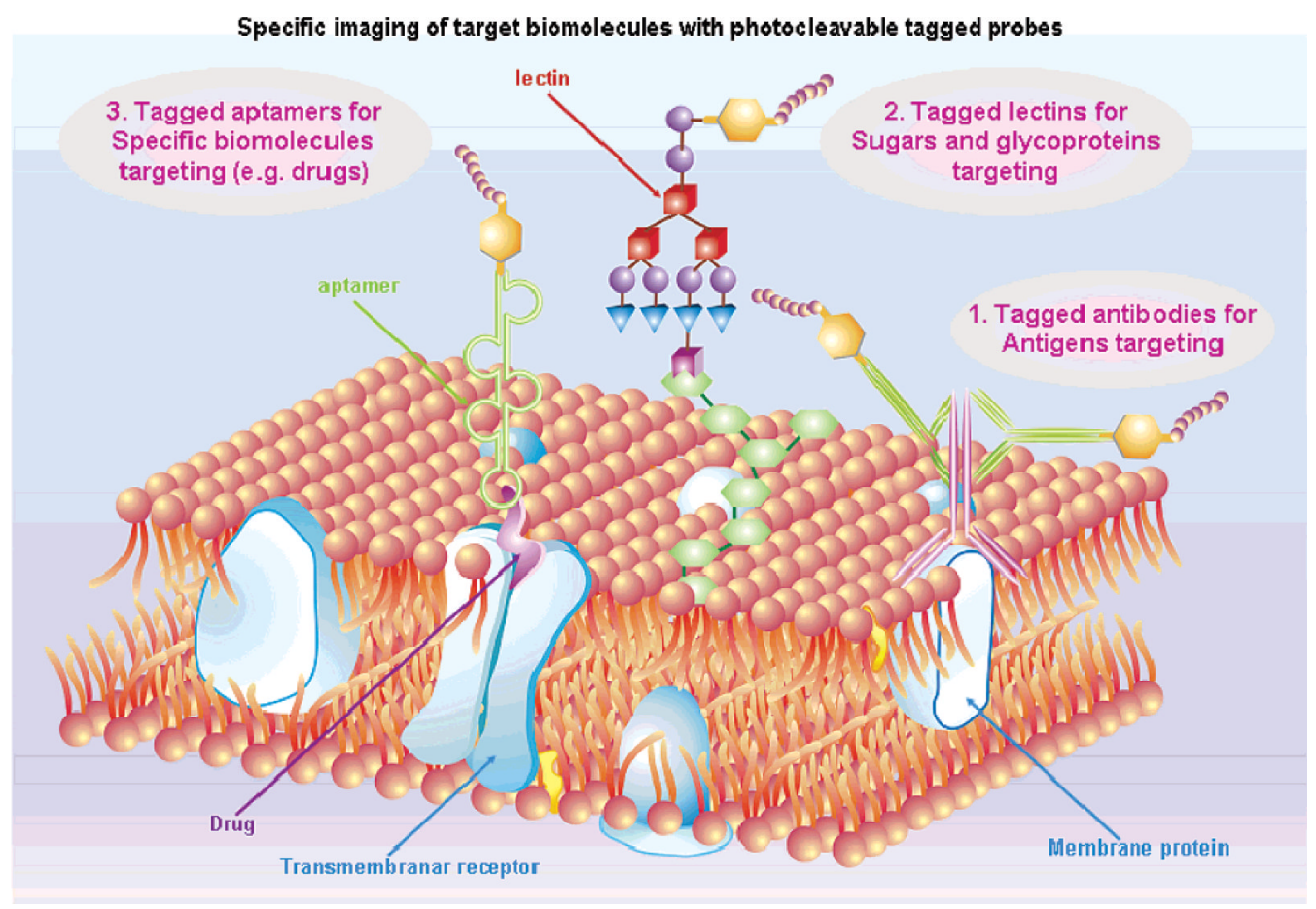

Figure 9.

Schematic representation of the concept of specific imaging for different target biomolecules and probes. 